\title{
Indigeneidad, descolonización y la paradoja del desarrollismo extractivista en el Estado Plurinacional de Bolivia
}

\author{
Indigeneity, decolonization and the paradox of extractive development \\ in the Plurinational State of Bolivia \\ RICKARD LALANDER ${ }^{1}$ \\ Universidad de Södertörn, Suecia
}

RECEPCIÓN: 10/02/2017•ACEPTACIÓN: 01/05/2017

RESUMEN: Históricamente, los pueblos indígenas fueron marginados y oprimidos en la economía política boliviana. En tiempos de Evo Morales en la presidencia y con la Constitución de 2009, la descolonización política, económica, social y cultural ha llegado a ser el proyecto central de la transformación del Estado y la sociedad. Por un lado, la nueva Constitución ha sido clasificada como una de las más progresistas del mundo en relación con los derechos étnicamente definidos. Los principios indígenas ético-filosóficos del Suma Qamaña/Vivir Bien, acerca de la relación armónica entre individuos y naturaleza fueron incorporados en la Constitución. Por otro lado, estos derechos colisionan con los derechos sociales más amplios (definidos por clase), e igualmente, con los derechos del Estado de extraer y comercializar los recursos naturales (en especial hidrocarburos y minería) bajo la bandera de la justicia redistributiva, reformas sociales y bien común, que en este estudio se define como la paradoja del desarrollismo extractivista. Este artículo se basa en un trabajo etnográfico y se problematiza el dilema extractivista y las tensiones entre derechos étnicos y derechos de clase. De esta manera, se aporta a los debates sobre la indigeneidad y ta los desafíos y dilemas de proyectos descolonizadores.

1. Doctor en Estudios Latinoamericanos. Catedrático e investigador de la Escuela de Ciencias Naturales, Tecnologìa y Estudios Ambientales, Universidad de Södertörn, Estocolmo, Suecia. Correo electrónico: rickard.lalander@sh.se. 
PALABRAS CLAVE: Bolivia - constitucionalismo - derechos étnicos derechos socio-económicos - descolonización - economía política - extractivismo - indigeneidad - vivir bien.

ABSTRACT: Historically, indigenous peoples have been marginalized and oppressed in the Bolivian political economy. During the presidency of Evo Morales, and under the 2009 Constitution, political, economic, social and cultural decolonization has become the central project for the transformation of the State and society. On the one hand, the new Constitution has been classified as one of the most progressive in the world with respect to ethnically defined rights; the indigenous ethical-philosophical principles of Suma Qamaña/Vivir Bien, referring to the harmonious relationship between individuals and nature, have been incorporated into the Constitution. On the other hand, these rights collide with broader social rights (defined by class) and also the rights of the State to extract and market natural resources (especially hydrocarbon extraction and mining) under the banner of redistributive justice, social reforms and the common good. This collision is defined in this study as the paradox of extractivist developmentalism. The article is based on an ethnographic work and problematizes the extractivist dilemma and the tensions between ethnic rights and class rights, thus contributing to debates about indigeneity and the challenges and dilemmas of decolonizing projects.

KEY WORDS: Bolivia - constitutionalism - ethnic rights - socio-economic rights - decolonization - political economy - extractivism - indigeneity - living well.

\section{Introducción}

En casi diez años de la revolución democrática cultural, Bolivia se ha convertido en un referente internacional, porque a la cabeza de los movimientos sociales impulsamos nuestro propio modelo económico, social, comunitario, con soberanía; recuperamos nuestros recursos naturales que nos permiten que los beneficios que se generan lleguen a todas las bolivianas y a todos los bolivianos (Evo Morales Ayma, discurso público, agosto 2015)².

2. Morales Ayma (2015a). 
En el contexto del proyecto descolonizador del gobierno boliviano de Evo Morales Ayma iniciado el 2006, el presente artículo trata sobre los desafíos relacionados con la gobernanza de recursos naturales (el extractivismo), las ambiciones de reformas sociales y el reconocimiento de derechos constitucionalmente establecidos. En particular, se analizan las tensiones de identificación entre los actores indígenas. En los debates de la (de-)colonialidad, se define la colonialidad como el "lado oscuro de la modernidad”. Desde la década de 1970 emergió la idea, entre pensadores de izquierda preocupados por las injusticias sociales y desigualdades Norte-Sur, la necesidad de descolonizar también el conocimiento. Consecuentemente, la descolonización requiere una desconexión también epistemológica y ontológica vis-a-vis la colonialidad occidental-euro-centrista ${ }^{3}$.

A partir de 2006, el proyecto primordial de la transformación del Estado y la sociedad ha sido la descolonización política, económica, social, cultural, epistemológica y ontológica. El proyecto descolonizador igual se refleja en la nueva Constitución boliviana de 2009, indudablemente entre las constituciones más radicales del mundo en cuanto a la incorporación de criterios internacionales de derechos humanos y el reconocimiento de derechos específicos de los pueblos indígenas ${ }^{4}$.

La concepción ética/filosófica del Suma Qamaña/Vivir Bien de los pueblos indígenas, acerca de la relación armoniosa entre seres humanos y la naturaleza/el ambiente, ha sido establecida como la columna vertebral de la Constitución y de las políticas nacionales de desarrollo. Estas reformas innovadoras han sido aplaudidas en el ámbito mundial y han mejorado la imagen étnico-ecologista de Bolivia y del gobierno de Evo Morales Ayma. En el fragmento del preámbulo de la Constitución, se declara que Bolivia no es más una república sino un Estado plurinacional, un reconocimiento directo de la costumbre indígena de organización de acuerdo con las distintas identificaciones étnico-culturales al interior del mismo Estado-nación:

“[Mediante esta Constitución] dejamos en el pasado el Estado colonial, republicano y neoliberal.

Asumimos el reto histórico de construir colectivamente el Estado Unitario Social de Derecho Plurinacional Comunitario, que integra y articula los

3. Mignolo (2002).

4. La reforma constitucional de Bolivia fue fuertemente influenciada por la Convención (Organización Internacional del Trabajo) OIT 169 sobre los derechos de los pueblos indígenas de 1989 y luego inspirada por la Declaración de los Derechos de los Pueblos Indígenas (2007) de las Naciones Unidas. 
propósitos de avanzar hacia una Bolivia democrática, productiva, portadora e inspiradora de la paz, comprometida con el desarrollo integral y con la libre determinación de los pueblos" 5 .

Históricamente, la economía política boliviana ha excluido a los pueblos indígenas. El capitalismo y el imperialismo minero y extractivista, basados en la explotación de los indígenas como fuerza de trabajo, han caracterizado la economía política boliviana desde la colonia ${ }^{6}$. La Constitución de 2009 fortaleció la posición y el papel del Estado en la economía, como respuesta al descontento con el capitalismo global neoliberal. El gobierno de Morales, junto con los de Venezuela y Ecuador, han protagonizado el proyecto que fue definido como el socialismo del siglo xxi. De forma reiterada, estos gobiernos han enfatizado que el Estado debe alcanzar el control de las empresas extractivas con el fin de financiar las políticas sociales y alcanzar el desarrollo económico.

Varios académicos definieron los alcances de las orientaciones políticas recientes de Bolivia (y de Ecuador) en términos de un proyecto postneoliberal o de neoextractivismo progresista ${ }^{7}$. Valga aclarar que el extractivismo en este artículo, se circunscribe principalmente a los sectores de hidrocarburos y minería. Una breve definición del extractivismo es: “...un tipo de extracción de recursos naturales, en gran volumen o alta intensidad, y que están orientados esencialmente a ser exportados como materias primas sin procesar, o con un procesamiento mínimo"8.

Regresando al tema de los derechos, no fueron solo los étnicamente definidos que se fortalecieron en la nueva Constitución y en la legislación secundaria durante el periodo de Evo Morales, sino también los derechos sociales más amplios; derechos socio-económicos; el derecho a unas condiciones dignas de vida y de bienestar, instrumentalizados a través de específicos programas sociales y otras políticas dirigidas a una justicia redistributiva, que en este estudio se denomina a veces como derechos definidos por clase. Respecto al control estatal de industrias vitales -principalmente hidrocarburos, agricultura y minería- la Constitución declara que la industrialización y comercialización de recursos naturales representan la prioridad clave del Estado, y que los ingresos sean destinados al bien común (artículos 319 y 355$)^{9}$.

5. Estado Plurinacional de Bolivia (2009), Preámbulo.

6. VeltMeyer (2014) p. 83.

7. Véase, por ejemplo: Escobar (2010); Artaraz (2012).

8. GUdynas (2015), p. 13.

9. Estado Plurinacional de Bolivia (2009). 
El objetivo de este artículo es el de examinar de modo analítico la compleja relación entre derechos étnicos y derechos sociales más amplios (definidos por clase) en el ámbito de la economía política boliviana de gobernanza de recursos naturales. Por ende, este artículo aporta a los debates acerca de la gestión contenciosa de recursos naturales y de las relaciones, contradicciones, tensiones entre clase, etnicidad y la cuestión de la indigeneidad ${ }^{10}$. Una afirmación esencial es que los derechos humanos basados definidos por clase en la práctica tienden a superar los definidos étnicamente, debido a la paradoja del desarrollismo extractivista.

El desafío de las autoridades del Estado es consecuentemente proveer bienestar social para todos, lo que requiere acceso a recursos económicos. Mediante el control estatal de las industrias estratégicas se puede lograr la redistribución de los ingresos derivados de la extracción y exportación de los recursos naturales, es decir, la provisión de derechos definidos por clase. No obstante, los derechos ambientales y de los pueblos indígenas se afectan en las situaciones de extracción de recursos naturales en territorios indígenas. Este dilema sigue la lógica que ha caracterizado a proyectos extractivistas en numerosos lugares del mundo, en la cual se subordinan los derechos étnico-culturales y ambientales-conservacionistas en relación con los intereses económicos. Las realidades económicas y políticoelectorales a corto plazo tienden a crear presiones sociales que el Estado percibe como más urgentes que la protección ambiental y de las comunidades indígenas. En un estudio anterior, se utilizó la metáfora de una "camisa de fuerza" para problematizar esta ecuación tan difícil de resolver para los gobiernos progresistas, sobre los derechos étnicos y ambientales en relación con las ambiciones de proveer reformas de bienestar mediante extractivismo ${ }^{11}$, para cumplir con los derechos definidos por clase social.

Por un lado, se analiza la compleja identidad política de la indigeneidad boliviana. Por el otro, se problematiza el dilema extractivista del gobierno boliviano, especialmente en relación con el discurso y a la justificación ética mediante la implementación de políticas extractivas por parte de las autoridades estatales y cómo estos discursos y justificaciones se relacionan con los elementos identitarios tanto de la clase como de la etnicidad. De este modo, el estudio considera cómo estas relaciones e identificaciones se perciben por los voceros indígenas en las bases o los niveles socio-políticos intermedio y nacional.

10. Postero (2007); Mcneish (2013); Fontana (2014).

11. LALANDER (2014). 
Mientras que se debate acerca de las identidades políticas bolivianas en medio de los recientes proyectos extractivistas, no se puede omitir un elemento identitario adicional; esto es, el rasgo ecologista de la identidad indígena. La dimensión ecologista es central en las recientes contestaciones políticas sobre proyectos extractivos. Si bien es cierto que los derechos étnicos evidentemente están separados de los derechos de la naturaleza/ambiente, en la práctica coinciden, con frecuencia, en escenarios extractivistas. Además, el rasgo ambiental o ecologista de los actores y de los intereses a veces está incorporado en la identidad étnica, como se clasificará más adelante.

Los instrumentos, tratados e instituciones internacionales, como la Convención 169 de la OIT (Organización Internacional del Trabajo) de 1989 y la UNDRIP (La Declaración de Naciones Unidas de los Derechos de los Pueblos Indígenas) de 2007 pueden ser poderosos, si solo son instrumentos simbólicos para la lucha indígena en todo el mundo. No obstante, en relación con el artículo 3 de la UNDRIP sobre el "derecho a la libre determinación de los pueblos indígenas", el cumplimiento de estos derechos depende de políticas específicas y leyes nacionales ${ }^{12}$.

Sin embargo, ni un sistema legal progresista, ni la ratificación de normas internacionales de derechos humanos relativas a los derechos de los indígenas pueden garantizar que estos derechos sean siempre priorizados en la práctica. Se encuentran contradicciones tanto en la Constitución, así como en el plan nacional de desarrollo, causando un choque entre los derechos étnicos y los objetivos de bienestar social (derechos definidos sobre la base de la clase). Como en el resto del continente, los derechos en el papel (de jure) no corresponden necesariamente a los derechos en la práctica $(\text { de } f a c t o)^{13}$.

Metodológicamente, el estudio se basa en un trabajo etnográfico de campo realizado en Bolivia entre el 2010 y el 2017. Se realizaron centenares de entrevistas semiestructuradas, aunque se mencionará solo una selección de ellas. El material etnográfico ha sido complementado por una lectura crítica de trabajos académicos anteriores y de documentos legales, discursos oficiales y la prensa boliviana. Valga aclarar, en cuanto a la lógica argumentativa a través del artículo, que será necesario simplificar un poco las tensiones entre la etnicidad y la clase entre los actores. Con el objetivo de ver con más claridad las particularidades de cada proceso o de cada componente identitario, es esencial realizar una simplificación relativa.

12. Belliera y Préaud (2012).

13. LALANDER Y KRÖGER (2016). 
La disposición del texto es la siguiente. Primero, se ofrece una sintética retrospectiva de la lucha del movimiento indígena boliviano, principalmente desde 1952 hasta hoy, enfatizando, en particular, la politización de la identidad étnica y la tensión entre clase y etnicidad. Luego, se examina la filosofía y política del Vivir Bien y después la naturaleza contradictoria de la Constitución de 2009, en particular aquellos artículos que reflejan los valores y los derechos de la clase y de la etnicidad y los derechos extractivos del Estado. Enseguida, se analiza brevemente la Ley Marco de la Madre Tierra y los rasgos ecologistas de los pueblos indígenas. A continuación, se examina el caso más emblemático de resistencia étnicoecologista contra las políticas extractivo-desarrollistas: el conflicto del TIPNIS. El caso del TIPNIS ilustra la contradicción entre las reivindicaciones de los derechos de los indígenas y las prácticas estatales. Antes de concluir el artículo con algunas conclusiones pertinentes, se problematizarán las tensiones entre la indigeneidad y la paradoja del desarrollismo extractivista a través del análisis de las posiciones relativas de distintos actores involucrados.

\section{La indigeneidad boliviana y la politización de la etnicidad en retrospectiva}

En diferentes partes de América Latina, especialmente en México y Perú, la ideología indigenista se difundió durante la primera mitad del siglo xx y fue una estrategia para lidiar con el "problema indígena". Intelectuales, sacerdotes y políticos no indígenas trabajaron para mejorar las condiciones sociales de las poblaciones indígenas, aunque típicamente con un estilo paternalista y clientelista y como un componente de la construcción de la nación basada en el mestizaje. Por ejemplo, el historiador Marc Becker concluye: "El indigenismo siempre fue una construcción de la cultura dominante, particularmente de las élites de mestizos intelectuales que utilizaron las cuestiones indígenas para avanzar sus propias agendas políticas". ${ }^{14}$

En Bolivia, el indigenismo se articuló ya en la década de 1920, con los intentos de integrar a los trabajadores indígenas y mestizos, realineando así la relación entre la clase obrera no indígena y los pueblos indígenas ${ }^{15}$. Sin embargo, la expresión más tenaz del indigenismo boliviano llegó con la Revolución Nacional de 1952 y la Reforma Agraria de 1953, protagonizada por el MNR (Movimiento Nacionalista

14. BECKER (1995).

15. Gray Molina (2007). 
Revolucionario). Hasta entonces, los pueblos originario-indígenas tanto en las tierras altas como en las tierras bajas se identificaban precisamente como indios, pero posteriormente fueron redefinidos como campesinos.

La revolución de 1952 trajo consigo una campesinización cultural de las comunidades indígenas y de sus prácticas culturales, con la disolución de las estructuras sociopolíticas y organizativas tradicionales. El decreto de la Reforma Agraria de 1953 significó, también, que se borrasen todas las menciones directas a los "pueblos indígenas", aimaras, quechuas, etc. ${ }^{16}$. En retrospectiva, el intelectual quechua y educador Leonel Cerruto explica lo siguiente:

"El 52 es un quiebre, porque no fue el movimiento indígena el que ha planteado el fraccionamiento y la propiedad individual de la tierra, sino que eso vino como una corriente de izquierda, viene copiado de México. Claro, el indigenismo [y sus eslóganes de] tierra para los campesinos, tierra para quien la trabaja. Entonces ahí comienza la campesinización también de los indígenas bolivianos. Pero, no deja de ser ni indígena, ni originario. No. Entonces, ahora ese problema subsiste. Hay que superar todavía eso" ${ }^{17}$.

Ya en las décadas de 1960 y 1970 las organizaciones intelectuales indígenas radicales reaccionaron ante esta usurpación y homogeneización cultural. Jóvenes estudiantes indígenas urbanizados se reunieron alrededor del escritor e intelectual quechua-aimara Fausto Reinaga, quien escribió y habló de la importancia de las raíces étnicas y culturales de los pueblos indígenas. Reinaga rechazó la identidad "campesinizada" y patrocinó un regreso a la indigeneidad. El antropólogo jesuita Xavier Albó sintetizó las reuniones con Reinaga: "Nos redujeron a campesinos, y nos arrebataron nuestra condición de Pueblo Aymara. ¡Volvamos a ser aymaras!” Estas actividades llevaron a la formación de dos movimientos paralelos: el Katarismo y el Indianismo respectivamente.

El historiador Pedro Portugal Mollinedo (de origen aimara) militó en el movimiento indianista y recuerda que mientras que el Indianismo acentuó los aspectos culturales, étnicos y nacionales de los pueblos indígenas, el Katarismo se concentró en las dimensiones económicas y sociales de la lucha ${ }^{19}$. Ambos movimientos -a veces

16. Gray Molina (2007), p. 6.

17. Cerruto, entrevista, El Alto, 23 de noviembre de 2015.

18. Albó (2009), p. 36.

19. Portugal Mollinedo, entrevista por internet, 10 de febrero de 2016. 
fusionados y ocasionalmente en oposición- desafiaron la retórica dominante de la clase campesina del periodo y en adelante produjeron en diferentes organizaciones y discursos políticos. Es importante enfatizar la estrategia de cambiar el significado de la "indianidad" y el epíteto peyorativo de "indio" a un símbolo reivindicativo positivo. Como se expresaban Reinaga y otros indianistas: "como indios nos oprimieron, como indios nos liberaremos".

Los indianistas se organizaron en sus propios partidos políticos en 1960 como el PAN (Partido Agrario Nacional), luego en 1968 como Movimiento Nacional Tupak Katari y en 1978 como MITKA/Movimiento Indio Tupak Katari ${ }^{20}$. La máxima figura histórica emblemática tanto del Indianismo como del Katarismo fue Túpak Katari que, antes de ser ejecutado por los españoles, lideró una rebelión indígena a principios de la década de 1780 junto con su amante Bartolina Sisa. En comparación, los kataristas fueron más exitosos en la lucha organizada campesina-indígena, con su partido Movimiento Revolucionario Tupak Katari/ MRTK. En la década de 1990 operó un movimiento guerrillero katarista armado: el Ejército Guerrillero Tupak Katari, que incluía nombres destacados como Felipe Quispe, quien posteriormente se convertirá en el presidente de la CSUTCB (Confederación Sindical Única de Trabajadores Campesinos de Bolivia) y el actual vicepresidente de Bolivia, Álvaro García Linera ${ }^{21}$.

El cambio político más reciente hacia la izquierdización del sistema político boliviano con Evo Morales en la presidencia, es el resultado de décadas de luchas de los movimientos sociales indígenas contra la política neoliberal, que dominó como doctrina económica desde 1985. La lucha del movimiento indígena es per se una propuesta de cambio sistémico y un rechazo del capitalismo global, del imperialismo y de la opresión a lo largo de las líneas de etnicidad y de clase. Una encrucijada de la lucha indígena ocurrió en 1990, cuando la confederación indígena de tierras bajas CIDOB (Confederación de Pueblos Indígenas de Bolivia) organizó la Marcha por el Territorio y la Dignidad desde Trinidad en las tierras bajas hasta La Paz. Los pueblos indígenas han luchado durante décadas por mayor autonomía y dignidad como pueblos, a partir del año 1989, incentivados por la Convención OIT 169. Además, se acentuó la presión de las organizaciones indígenas de las tierras altas durante este periodo. A pesar del contexto neoliberal, en la década de 1990 se efectuaron varios reconocimientos legales de las reivindicaciones étnicamente definidas,

20. Para una valiosa documentación detallada de este periodo formativo del movimiento indianista-katarista, véase: Portugal Mollinedo y Macusaya CruZ (2016).

21. Albó (2009), pp. 36-40. 
como la Ley de Participación Popular/LPP de 1994 y la aprobación de Las Tierras Comunitarias de Origen/TCO. La ratificación boliviana de la OIT-169 en 1991 fue el resultado de la marcha de la CIDOB en 1990. Sin embargo, la aplicación concreta de la OIT 169 y el derecho más amplio a las consultas previas sobre las actividades de hidrocarburos en Bolivia se aplazaron hasta 2007, es decir, luego de la instalación presidencial de Evo Morales ${ }^{22}$.

El periodo hasta 2003 se caracterizó por actividades de protesta contra el neoliberalismo; bloqueos viales, manifestaciones callejeras, huelgas, etcétera, y las organizaciones indígenas fortalecieron su protagonismo. A los albores del nuevo milenio, el creciente movimiento alrededor de Morales estuvo en el epicentro de varios conflictos por los recursos, más vigorosamente durante la llamada "guerra del agua" (protestas contra la privatización del agua) en Cochabamba en 2000 y durante la "guerra del gas" (contra la exportación de gas a Estados Unidos a través de Chile) en El Alto-La Paz en 2003, que se concluyó con la renuncia del presidente neoliberal Gonzalo Sánchez de Lozada ${ }^{23}$.

\section{¡Ahora los movimientos sociales e indígenas somos gobierno!}

En diciembre de 2005, Evo Morales, líder de los campesinos productores de coca, fue elegido presidente de Bolivia, el primer Presidente indígena de América Latina, en representación del movimiento político MAS-IPSP (Movimiento Al SocialismoInstrumento Político por la Soberanía De los Pueblos), que fue una creación de los principales movimientos sociales indígena-campesinos bolivianos. La elección de Morales puede ser vista como la culminación de un ciclo de protesta en contra de las estructuras políticas y económicas excluyentes y también como reconocimiento de ciudadanos y colectivos ya marginados (principalmente indígenas y obreros "pobres").

Silvia Rivera Cusicanqui es una emblemática socióloga Aimara. Ella ilustra la complejidad epistémica del colonialismo y la opresión histórica de los pueblos indígenas:

"El tema de la dignidad, por ejemplo, es tan central para la opresión andina, ya que con una sola palabra se evoca oprimido u opresión y explotar, que en aymara es una sola palabra: 'empequeñecer'. Y ese es el tema de la dignidad humana, es decir, todo aquello que te rebaja la dignidad humana (sea un

22. SCHILLING-VACAFLOR (2013), p. 207.

23. Por ejemplo: Albó (2009), pp. 43-67. 
mal salario o un mal trato) te empequeñece como persona. Es un concepto poderosísimo, y disminuye tu potencial como ser humano. Es por esto que la gente se levanta. La gente no se levanta a causa de las fuerzas productivas, se levantan porque les pisaron el poncho o les escupieron al recibir la limosna. Igual en quechua tiene que ver con la palabra 'pisotear' en relación con el que te oprime. Hay que poner el cuerpo, no hay otra" 24 .

Indudablemente, durante la era de Morales ha tenido lugar una relativa dignificación de los indígenas bolivianos. Si bien el racismo y la discriminación de los ciudadanos indígenas siguen existiendo como enfermedades principales de la sociedad boliviana, ser indígena no es, sin embargo, un obstáculo persistente, en comparación con las épocas pre-Evo. Bajo la bandera de la descolonización, se ha producido una gradual transformación de la sociedad, con mejoras en el reconocimiento étnicamente definido. Una broma común durante los primeros años de Morales en el poder era que antes de ir a una entrevista de trabajo, lo mejor era vestirse primero con un poncho u otros símbolos étnicos.

Para algunos estudiosos, se produjo una redefinición de la ciudadanía campesino-indígena y de la connotación de la nación boliviana. Esto se logró a través de la lucha combinada de las organizaciones indígena-campesinas de base y del instrumento político-electoral (MAS-IPSP, en adelante denominado MAS) que a través de los canales de la democracia representativa logró ocupar el Estado ${ }^{25}$.

Las principales organizaciones del movimiento indígena boliviano tienen diferentes perfiles relativos a la identificación en términos tanto de clase como de etnicidad. Tradicionalmente, se asocia a la CIDOB de las tierras bajas con un perfil étnico, reflejado en su nombre: Confederación de Pueblos Indígenas de Bolivia. La otra organización más ética e indígena o, incluso, originaria, es el CONAMAQ (Consejo Nacional de Ayllus y Markas del Qullasuyu). Las cuatro organizaciones restantes tienen un perfil más bien clasista, no obstante al mismo tiempo indígena: la COB (Central Obrera Boliviana), la ya mencionada CSUTCB, e igualmente la organización de las mujeres campesinas; la Confederación Nacional de Mujeres Campesinas Indígenas Originarias de Bolivia Bartolina Sisa (las Bartolinas), y los interculturales, la CSCIB (Confederación Sindical de Comunidades Interculturales de Bolivia) ${ }^{26}$. El

24. Rivera Cusicanqui entrevistada en Arteaga y MuÑoz (2014).

25. Véase, por ejemplo, García Yapur et al. (2014).

26. Ibid. 
sostén de la CSCIB se constituye por los migrantes cocaleros, que originalmente son del altiplano, pero que desde varios años se han establecido también en las tierras bajas y la Amazonía. Estas cuatro organizaciones apoyan al gobierno del MAS, mientras que el CONAMAQ y la CIDOB se han dividido ${ }^{27}$. No obstante, las seis organizaciones participaron en el proceso de rescribir la Constitución.

A pesar de mi argumentación anterior sobre la clase y la etnicidad como complejamente fundidas en todas las organizaciones aquí mencionadas -y considerando que las diferencias frecuentemente tienden a ser más semánticas- es interesante observar que algunos autores hagan una diferencia entre indígenas y originarios y clasifiquen al CONAMAQ como originarios y la CIDOB como indígenas. Originario en este sentido es según esa lógica entendido como un grado más exclusivo y auténtico de la indigeneidad.

Las Bartolina Sisa están etiquetadas como campesinas/clasistas, pero incluye tanto indígena como originario en su nombre organizativo ${ }^{28}$. La CSUTCB nació del movimiento katarista, aunque respaldada por la Iglesia Católica, ONG y partidos políticos izquierdistas ${ }^{29}$. Hay que enfatizar firmemente la importancia de la CSUTCB en el proceso reivindicativo de los pueblos indígenas bolivianos. A pesar de ser clasificada como una organización campesina clasista, el elemento étnicocultural es central en la confederación y en la CSUTCB se iniciaron varios debates y conceptualizaciones que llegaron a ser fundamentales en el proceso que culminó en la refundación del Estado, como el discurso de la plurinacionalidad. En uno de sus primeros documentos oficiales, la tesis política de la confederación en 1979, la identidad organizativa se expresa como "campesinos aymaras, quechuas, campas, chapacos, chiquitanos, moxos, tupiguaranés y otros" ${ }^{30}$, es decir, tanto campesino e indígena. De acuerdo con sus actuales estatutos de organización (art. 3.1), la CSUTCB es:

“... la máxima organización natural e histórica que representa al conjunto de las naciones y pueblos indígena originario campesinos de todo el Estado Plurinacional donde surgen las luchas históricas libradas por los movimientos

27. Desde diciembre de 2013, CONAMAQ se divide en una facción que apoya al gobierno de Morales y una otra en oposición. Ya a fines de 2010, CIDOB está dividida y actualmente hay dos CIDOB, una a favor del gobierno y otra en oposición.

28. FonTANA (2014) pp. 305-307.

29. Portugal Mollinedo, entrevista por internet, 10 de febrero de 2016.

30. Аlbó (2009), p. 39. 
indígena originario campesinos, en la búsqueda de la liberación del Estado colonialista y republicano" ${ }^{31}$.

Ya en 1994, CSUTCB se acordó con la estrategia de formar un "instrumento político", específicamente para poder "crear nuestro propio Estado, con nuestra propia Constitución, con la cual las naciones indígenas puedan producir su propio Estado" y esta reunión puede ser considerada el embrión de la ruta hacia la Constitución de $2009^{32}$.

\section{El Vivir Bien}

“... Estamos saliendo de esa lógica de la modernidad que nos hace reencontrar y tenemos que entrar en esa otra lógica de la cultura de la vida, de cuidar la vida: el Vivir Bien, el Buen-Vivir. Eso nos va a dar horizontes, no solamente a Bolivia sino al mundo de que podemos despertar de una manera distinta. Los estados tienen retos ahora muy importantes. No pueden continuar con el extractivismo, no pueden continuar con el deterioro de la madre tierra. Pero, cómo entramos ahora en una nueva lógica, también para que todos tengan trabajo, para que todos también tengan comida, es un reto verdadero. Por eso también nosotros insistimos en que la cosmovisión ancestral de los pueblos indígenas-originarios viene más después. Porque en el horizonte de los pueblos indígenas-originarios la vida es lo más importante, no solamente el dinero. Porque la vida es el factor sustancial de las cosmovisiones ancestrales de las culturas indígenas originarias" ${ }^{33}$.

En la nueva Constitución boliviana los principios ético-filosóficos indígenas de Suma Qamaña (aimara) -traducido en español a Vivir Bien- se incorporaron como columna vertebral, así como posteriormente en los planes nacionales de desarrollo. Como se expresa en la cita de arriba del abogado e investigador aimara, Fernando Huanacuni Mamani -uno de los principales intelectuales especializados en el Vivir Bien, y a partir de 2017 el canciller de Bolivia- la propuesta del Vivir Bien, desde el horizonte de las cosmovisiones ancestrales de los pueblos indígenas,

31. CSUTCB (2010).

32. Artaraz (2012), p. 45.

33. Huanacuni Mamani, entrevista, La Paz, 26 de agosto de 2016. 
es una fuerte crítica directa de las lógicas y costumbres asociadas a la modernidad occidental. Tal como la expresan a menudo Evo Morales y el ex-Canciller (20062016) boliviano David Choquehuanca (que también es aimara), la idea es vivir "bien” y no "mejor" (a costa de los demás), es decir, no luchar por la acumulación material y económica, para mejorar "las condiciones de vida" en el ámbito personal, más que los vecinos, etcétera. Valga enfatizar el valor simbólico y estratégico de la filosofía del Suma Qamaña-Vivir Bien en el ámbito global, y como un mensaje al mundo sobre la necesidad de cambiar el rumbo y encontrar opciones al capitalismo global y la crisis climática. Este valor simbólico y estratégico se confirma claramente por el mismo hecho de la presencia de dos voceros del Vivir Bien como ministros de relaciones exteriores. La facción más ecológicamente preocupada del gobierno -los pachamamistas - tiene su origen histórico en un grupo dentro del movimiento indianista de algunas décadas atrás ${ }^{34}$. Por cierto, Choquehuanca se ha identificado públicamente como Indianista ${ }^{35}$, mientras que Huanacuni Mamani más bien tiene su origen en la CSUTCB y el Katarismo.

Los defensores del Suma Qamaña sugieren que el desarrollo/progreso, como la mayoría de la gente lo entiende, no es necesario. Tanto el "progreso" individual como el progreso y el “bienestar” económico nacional relativo a los bienes materiales y la acumulación de capital, de acuerdo con las nociones tradicionales de desarrollo, deben compararse con una vida en armonía con el ambiente y con los otros seres humanos, sin las cargas del capitalismo mundial sobre las naciones y del consumismo sobre los individuos y las colectividades. Académicos, activistas de los movimientos sociales y políticos en Bolivia, Ecuador y otros lugares utilizan con frecuencia el concepto de Vivir Bien; tanto como una crítica al desarrollo (entendido como progreso/crecimiento económico), como referidos a principios de vida armoniosa y ecológicamente sostenible ${ }^{36}$.

No obstante, el Suma Qamaña-Vivir Bien evidentemente no fue inventado ni por el gobierno de Evo Morales ni por los voceros intelectuales aimaras mencionados, Huanacuni Mamani y Choquehuanca, si bien es cierto que estas personas han aportado en la internacionalización de la conceptualización. Una fase del proceso de una intelectualización más sistemática del Suma Qamaña se inició al

34. Portugal Mollinedo, entrevista por internet, 10 de febrero, 2016. Véase también: Portugal Mollinedo (2017).

35. Monasterios et al. (2007), p. 28. Sin embargo, Choquehuanca no era un militante del movimiento histórico indianista. Más bien, él se formó a través del activismo en algunas ONG.

36. Por ejemplo: Gudynas (2011); Artaraz y Calestani (2015). 
final de década de 1970 mediante los esfuerzos intelectuales del sociólogo aimara Simón Yampara. Su origen de lucha fue en el movimiento katarista y la CSUTCB. Él recuerda cómo le emergió la conceptualización del Suma Qamaña cuando era estudiante de Sociología durante esa época del final de la década de 1970.

“Estudiábamos Marx, todo era Marx, Marx, y no entendía muy bien esa teoría. ¿En Aymara, como decimos eso? Esa era mi pregunta. Tengo que buscar una palabra que exprese economía, si la economía es el motor de la sociedad y la lucha de clase, como nos tratamos así parece que la lucha de clases, ni la economía es tan importante entre los aymaras y en mí. Entonces yo saqué esto de qué dicen de familias en la constitución de la pareja humana, ahí es donde dan una serie de recomendaciones, de tener una buena vida, convivencia con los otros actores, no solo se van a preocupar de ustedes nomás, no tienen que hacer llorar a su papá, a su mamá, ni dar dolor de cabeza al padrino, etc... Como la conclusión de todos los sermones de recomendaciones, dije: 'Bueno, aquí está entonces la palabra, porque es Sumaq, una palabra'. Ya, y ese es el origen del Suma Qamaña. Entonces, al profesor le dije: 'Pero aquí no nos comunicamos con la economía, nos comunicamos más bien por este Suma Qamaña'. Pucha, todo el mundo me miraba, raro, se mofaban" 37.

Reconectando a las palabras mencionadas por Huanacuni Mamani sobre las visiones del Vivir Bien/Suma Qamaña, se reflejan las contradicciones y tensiones desde la perspectiva de los derechos definidos por clase. El mismo Huanacuni Mamani reconoce esta complejidad en la lógica del Vivir Bien en un país con índices altos de pobreza. En una entrevista de 2015 le pregunté si la visión y la política del Vivir Bien/Suma Qamaña también incluyen mecanismos para garantizar un nivel mínimo de dignidad humana:

“Exactamente, si no tenemos dignidad, no vamos a poder hablar del Vivir Bien. Entonces, hay todavía la deuda histórica que se ha convertido en deuda social y en deuda económica. ¿Quién la asume? El gobierno, los estados plurinacionales, recuperan sus capacidades, su capacidad social, capacidad de cuidar la vida, que es algo importante para empezar la redistribución. En eso obviamente están, en un proceso que todavía no hemos completado" 38 .

37. YAmpara, entrevista, La Paz, 14 de abril de 2014.

38. Huanacuni Mamani, entrevista, La Paz, 13 de abril de 2015. 


\section{Derechos étnicos y la paradoja extractivista en la Constitución de 2009}

Para una mejor comprensión del marco legal, de las complejidades del dilema del desarrollo extractivo, de los derechos étnico-indígenas así como de los derechos sociales más amplios, es muy importante examinar algunas partes cruciales de la Constitución de 2009, para visibilizar los derechos “desarrollistas extractivos" del Estado.

Como se mencionó en la introducción, la nueva Constitución declara que Bolivia ya no es una república, sino un Estado Plurinacional. El carácter plurinacional de la "refundada" Bolivia abarca varias dimensiones. La primera está relacionada con la descolonización y con el reconocimiento histórico-simbólico del pluralismo jurídico, las autonomías indígenas paralelamente a la división político-territorial tradicional del Estado, así como a una más amplia reconfiguración de la sociedad política basada en la participación indígena. Otro elemento es, precisamente, la pluralidad de las naciones, que promueve el derecho de las diferentes naciones indígenas de articular las demandas políticas y administrar la justicia dentro de la nación boliviana ${ }^{39}$.

Una novedad del texto constitucional se relaciona con los conceptos identitarios centrales de este estudio. Cada vez que se cita uno de los pueblos étnicamente definidos, los indígenas se juntan con campesinos y originarios: indígena-campesinoindígena, es decir, como pueblos indígenas campesinos originarios. Esta innovación se discutirá más adelante.

La identidad indígena y los específicos derechos indígenas se detallan en los artículos 30-32, por ejemplo, el derecho a la autodeterminación y la territorialidad. En cuanto a quién va a ser clasificado como indígena, la primera parte del artículo 30 declara:

"Es nación y pueblo indígena originario campesino toda la colectividad humana que comparta identidad cultural, idioma, tradición histórica, instituciones, territorialidad y cosmovisión, cuya existencia es anterior a la invasión colonial española”.

Más adelante, en el mismo artículo, se menciona el derecho a la consulta previa, libre e informada de los pueblos indígenas afectados por actividades extractivistas:

39. WaLsh (2009). 
“A ser consultados mediante procedimientos apropiados, y en particular a través de sus instituciones, cada vez que se prevean medidas legislativas o administrativas susceptibles de afectarles. En este marco, se respetará y garantizará el derecho a la consulta previa obligatoria, realizada por el Estado, de buena fe y concertada, respecto a la explotación de los recursos naturales no renovables en el territorio que habitan".

El derecho a la consulta previa de los pueblos indígenas afectados por actividades extractivas en sus territorios es un componente crucial de la paradoja del desarrollo extractivista. Si bien es cierto que este mecanismo legal basado en los derechos ha sido una práctica más frecuente en Bolivia que en la mayoría de los países vecinos latinoamericanos, estos procedimientos se han caracterizados por numerosas deficiencias, como la insuficiencia de poder decisivo y de información por parte de la población involucrada e, igualmente, irregularidades y falta de transparencia en términos de pagos de compensación ${ }^{40}$.

Otro reconocimiento importante de los derechos indígenas es la Autonomía Indígena Originaria Campesina (artículos 289-296), acompañada por la legislación secundaria en 2009. Aunque, como sostiene Andrew Canessa, el gobierno resistió a las ambiciones de numerosas comunidades indígenas que trataron de alcanzar el Estado de municipios indígenas autónomos a través de un referéndum. La explicación del gobierno era principalmente que "el Estado era ya indígena" y la unidad de los pueblos indígenas estaba en juego si continuaban con el procedimiento ${ }^{41}$.

Se expresa la protección de los parques naturales y los territorios indígenas en el artículo 385, mientras que los derechos territoriales de los pueblos indígenas están formulados en los artículos 394-395:

“El Estado reconoce, protege y garantiza la propiedad comunitaria o colectiva, que comprende el territorio indígena originario campesino, las comunidades interculturales originarias y de las comunidades campesinas. La propiedad colectiva se declara indivisible, imprescriptible, inembargable, inalienable e irreversible y no está sujeta al pago de impuestos a la propiedad agraria. Las comunidades podrán ser tituladas reconociendo la complementariedad entre derechos colectivos e individuales respetando la unidad territorial con identidad".

40. SCHILLING-VACAFLOR (2013).

41. Estado Plurinacional de Bolivia (2009) capítulo vii; Canessa (2014), p. 167. 
No obstante, paralelamente a los derechos colectivos indígenas, se expresa una cantidad de derechos individuales y universales (de los cuales algunos tienen raíces culturales indígenas), como en el artículo 8:

"El Estado se sustenta en los valores de unidad, igualdad, inclusión, dignidad, libertad, solidaridad, reciprocidad, respeto, complementariedad, armonía, transparencia, equilibrio, igualdad de oportunidades, equidad social y de género en la participación, bienestar común, responsabilidad, justicia social, distribución y redistribución de los productos y bienes sociales, para vivir bien”.

En términos generales, a lo largo de la Constitución se hace referencia a los objetivos centrales de la reducción de la pobreza, la provisión de bienestar social, desarrollo económico y protección del ambiente (por ejemplo, el artículo 312). Por otra parte, los artículos 306 y 313 hacen hincapié en que la ambición primordial de las políticas económicas de Bolivia es superar la pobreza y la exclusión social/ económica [derechos definidos por clase]; en consecuencia, se identifican los siguientes subobjetivos:

“1. Generación del producto social en el marco del respeto de los derechos individuales, así como de los derechos de los pueblos y las naciones.

2. La producción, distribución y redistribución justa de la riqueza y de los excedentes económicos.

3 La reducción de las desigualdades de acceso a los recursos productivos".

Pero, como se mencionó en la introducción, la misma Constitución también establece los derechos del Estado de explorar los recursos naturales del subsuelo, como se destaca en los artículos 319 y (abajo) 355, en los cuales igualmente se indica el destino de los ingresos derivados de estas actividades:

I. "La industrialización y comercialización de los recursos naturales será prioridad del Estado.

II. Las utilidades obtenidas por la explotación e industrialización de los recursos naturales serán distribuidas y reinvertidas para promover la diversificación económica en los diferentes niveles territoriales del Estado. La distribución porcentual de los beneficios será sancionada por la ley.

III. Los procesos de industrialización se realizarán con preferencia en el lugar de origen de la producción y crearán condiciones que favorezcan la competitividad en el mercado interno e internacional". 
Fuertes intereses económicos colisionan manifiestamente con el reconocimiento y la protección de los derechos constitucionales de los pueblos indígenas y la naturaleza. Este enigma -derechos reforzados y la continuación de la dependencia en la extracción de recursos naturales- se expresa de forma clara en la Constitución. Las autoridades nacionales justifican su posición en cuanto al persistente extractivismo con la necesidad de alcanzar justicia redistributiva, es decir, la disminución de la pobreza y la provisión de bienestar para todos, especialmente para los sectores marginados. En ocasiones, se ha referido a esta aproximación -con el sacrificio parcial de los derechos específicos del ambiente/ la naturaleza y los pueblos indígenas para alcanzar bienestar social- como un modelo de neoextractivismo progresista ${ }^{42}$.

\section{La Ley de la Madre Tierra y los rasgos ecologistas de los pueblos indígenas}

Reconectando al Vivir Bien y el perfil étnico-ecologista de Bolivia, en 2010 se sancionó la "Ley de Derechos de la Madre Tierra". La ley fue elaborada, primero, en colaboración con diferentes intelectuales, diputados y organizaciones sociales desde el año 2009. En ella se incluyen, entre otros, los siguientes derechos: mantenimiento de la integridad y los procesos naturales, prohibición de estructuras celulares modificadas o genéticamente alteradas, continuación de los ciclos vitales, agua pura y aire limpio, libertad de contaminación tóxica y radioactiva y el derecho de no ser afectados por megainfraestructuras y proyectos de desarrollo que disturben el balance de los ecosistemas y las comunidades locales.

A fines de 2012 la ley fue modificada por el legislativo nacional como la Ley Marco de la Madre Tierra y Desarrollo Integral para Vivir Bien ${ }^{43}$. El carácter de "Ley marco" significa que tiene un rango superior a las otras leyes. Por ejemplo, la legislación sobre minería, hidrocarburos, agua, etcétera, deben corresponder al contenido de la Ley Marco. Debe enfatizarse la segunda parte de la ley: el desarrollo integral, que alude a los objetivos del Vivir Bien, más allá de las ambiciones ambientales y los derechos propios de la naturaleza y los pueblos indígenas. Si bien los propósitos ambientales son centrales, el componente del desarrollo integral agrega una dimensión pragmática, ya que se consideran al mismo tiempo los derechos y necesidades

42. Gudynas (2015).

43. Estado Plurinacional de Bolivia (2012). 
de todos los seres humanos, es decir, desde los valores e intereses antropocéntricos ${ }^{44}$, como los derechos socioeconómicos, definidos por clase.

La ministra boliviana de Ambiente, Alexandra Moreira (que no es indígena), expresa la importancia de las tradiciones y creencias indígenas en el contexto de las relaciones entre los seres humanos y el ambiente y la gobernanza ambiental:

“... Lo que nosotros ahora llamamos ecología, en nuestra cultura milenaria también se ha caracterizado por el respeto, la conservación y esta actitud de reciprocidad que nosotros tenemos respecto a la madre tierra. La madre tierra nos da la vida, nos da alimentos, nos da salud. Entonces, en reciprocidad nosotros también tenemos un cierto comportamiento con ella. Evidentemente, en los últimos años, por la modernización se ha ido perdiendo, en generación tras generación, ese respeto y esa cultura de vida que nosotros teníamos con los antepasados. Sin embargo, como somos una cultura mezclada con pueblos indígenas, con pueblos andinos, persiste aún. Por eso tenemos algunos ritos, por ejemplo, como es la Pachamama, y la chaya, todo eso que tú le estás dando a la Pachamama en agradecimiento..." ${ }^{45}$.

La antropóloga Nicole Fabricant critica firmemente el componente de la indigeneidad en los discursos basados en el ecologismo y en las formas de vida sostenibles de la población indígena, pues estos se basan en las poblaciones rurales, que tienen una estrecha relación con el territorio. Por lo tanto, cuestiona la relevancia de estas lógicas para la gran parte de población indígena urbana. De igual forma, se muestra escéptica vis-à-vis el Vivir Bien como opción y estrategia proporcionada para hacer frente a la crisis climática ${ }^{46}$.

De todos modos, es importante reflexionar críticamente sobre el posible carácter ecologista de los pueblos indígenas. La noción del "nativo ecológico" se ha utilizado en los discursos públicos tanto por el gobierno de Morales y, como por los activistas indígenas de oposición. Sin embargo, el que estas características identitarias de los indígenas sean naturales, intrínsecas o automáticas podría cuestionarse. Para algunos estudiosos, el "indígena ecológico" es uno de los mitos más antiguos de la Antropología ${ }^{47}$, o podría entenderse como identidades parcialmente construidas, es

44. LALANDER (2015), pp. 126-127.

45. Moreira, entrevista, La Paz, 14 de abril de 2015.

46. FABRICANT (2013), p. 160.

47. KRECH III (1999). 
decir, a través de la fusión estratégica de los discursos indígenas y ecologistas en el ámbito local y transnacional. Como Astrid Ulloa argumenta de modo convincente, las organizaciones indígenas han sido percibidas de forma exitosa en todo el mundo como los defensores principales de los intereses de la Madre Tierra, como se puede observar con frecuencia en las cumbres climáticas internacionales ${ }^{48}$. Evidentemente, el autor no intenta afirmar que la preocupación ambiental de las organizaciones indígenas no debería considerarse como reivindicaciones serias. Pero no debería tomarse completamente por sentado que esta preocupación ecologista sea automática. Los pueblos indígenas no son un grupo homogéneo y otras preocupaciones basadas en la identidad pueden ser más relevantes en situaciones específicas, como las cuestiones de la pobreza y la discriminación étnica.

Los activistas intelectuales indígenas de la ONG boliviana NINA, Edwin Ejército Balcazar y Walter Orellana Limache, aclaran que ecologismo generalmente no constituye el elemento superior de la identidad indígena, pero, al mismo tiempo, los pueblos indígenas tienden a reaccionar cuando los proyectos extractivos amenazan sus sistemas de vida tradicionales de subsistencia ${ }^{49}$.

\section{El conflicto de la carretera del TIPNIS}

Desde el año 2011, el caso del TIPNIS (Territorio Indígena y Parque Nacional Isiboro Secure) ha sido el conflicto étnico-ambiental más emblemático de Bolivia. Es un territorio que se caracteriza por su biodiversidad, donde viven allí los pueblos indígenas mojeño-ignacianos, yuracarés y chimánes, entre otros. Entre el 15 de agosto y el 19 de octubre de 2011, una cantidad grande de activistas indígenas y noindígenas caminaron por sesenta y cinco días desde las tierras bajas hasta La Paz, manifestando su protesta contra el proyecto de construcción de una carretera de $602 \mathrm{~km}$, que conectaría el departamento del Beni, en las tierras bajas, con Cochabamba, en la Sierra, y que traspasaría el TIPNIS. La población que vive en este territorio está dividida. Hay grupos indígenas en la zona que apoyan la carretera, como los migrantes cocaleros que ven oportunidades económicas con la mejora de la infraestructura. La visión y los discursos del gobierno tienen que ver con políticas de bienestar social y, como se arguye, el TIPNIS necesita esa carretera para que mejoren las condiciones de vida de la población aislada en términos de acceso a salud, educación, etcétera.

48. Ulloa (2005).

49. Armata Balcazar y Limache Orellana, entrevista, La Paz, 18 de diciembre de 2015. 
La carretera formó parte de una estrategia latinoamericana de integración regional por parte de los nuevos gobiernos progresistas. Brasil estuvo involucrado desde el inicio para acelerar el proyecto de construcción, para mejorar el acceso a los mercados de la costa pacífica. La Iniciativa para la Integración de la Infraestructura Regional Suramericana - Consejo de Infraestructura y Planeamiento (IIRSA-COSIPLAN), es un proyecto estratégico de integración regional para el bien común (reformas de bienestar) que forma parte de los esquemas de UNASUR. El Banco de Desarrollo de Brasil financió el proyecto de la carretera por el TIPNIS y una empresa brasilera de construcción fue contratada, lo que junto con los intereses estratégicos de la empresa petrolera PETROBRAS en el proyecto ilustra la transformación geopolítica del continente. El vicepresidente García Linera rechazó firmemente la conexión entre el proyecto IIRSA y la carretera del TIPNIS ${ }^{50}$.

Los manifestantes -encabezados por la organización territorial Subcentral TIPNIS y las confederaciones indígenas CIDOB y CONAMAQ- presentaron una lista de dieciseis demandas concernientes al respeto por su territorio, así como otras reivindicaciones sociales, económicas y culturales. Después de algunos enfrentamientos violentos entre las fuerzas policiales y los manifestantes, el presidente Morales aceptó todas las instancias presentadas. Sin embargo, después de unos meses el proyecto de la carretera fue reiniciado, a pesar de la fuerte resistencia y de la cobertura mediática y académica internacional ${ }^{51}$.

Celso Padilla es presidente de la Asamblea del Pueblo Guaraní/APG. Durante la marcha pronunció lo siguiente:

"Queremos decirle al gobierno que este es el Estado Plurinacional. Aquí están los 34 pueblos. Queremos decirle al presidente Evo Morales que el Estado se construye con estos pueblos. No se debe concentrar el poder solamente en la CSUTCB, en las 'Bartolinas' y en las comunidades interculturales. Que estos pueblos son los que lo han levantado y lo han llevado al poder. ¿Por qué se olvida tan rápido?” ${ }^{2}$.

50. García Linera (2012), pp. 58-65.

51. Véase, por ejemplo: Fundación Tierra (2012); MCneish (2013). La marcha de 2011 no fue ni la primera ni la última marcha en defensa del TIPNIS. En 2012 se realizó una manifestación similar, pero no tuvo el mismo éxito en atraer participación y cobertura mediática en comparación con la marcha de 2011.

52. Fundación Tierra (2012), p. 55. 
Debe enfatizarse que Padilla se refiere directamente al "faccionalismo" de los movimientos indígenas y menciona a los tres más devotos partidarios de los gobiernos de Morales (CSUTCB, Bartolinas e Interculturales, es decir, las organizaciones más intensamente clasistas, en comparación con el perfil étnico de CIDOB al que está asociado el APG).

El conflicto del TIPNIS luego terminó temporalmente de una manera extraña. Durante entrevistas realizadas en La Paz en enero y febrero de 2014, varias autoridades del Estado me reafirmaron que se había suspendido el proyecto de la carretera, como resultado de una declaración emitida por el vicepresidente Álvaro García Linera. Fue el 4 de enero de 2014 que la prensa boliviana comunicó que el Vicepresidente se había formulado sobre el destino del TIPNIS en una conferencia en Buenos Aires en junio de 2013, es decir, medio año antes ${ }^{53}$. García Linera reconoció varios errores cometidos por el gobierno referente a la comunicación con los pueblos afectados. Acentuó que la carretera tendría que construirse, pero debería posponerse unos veinte, cincuenta o cien años y tendría que ejecutarse muy cuidadosamente respecto de la protección ambiental ${ }^{54}$.

Sin embargo, esta posición del gobierno se alteró rápidamente después de las elecciones presidenciales de octubre de 2014, cuando Morales fue reelegido de nuevo por un triunfo electoral aplastante. Así, el gobierno decidió una vez más avanzar con la carretera TIPNIS. Además, el 20 de mayo de 2015, Morales redactó y estableció un decreto presidencial que alteró de forma profunda las reglas del juego político en las áreas protegidas, algunas de las cuales son también territorios indígenas. Morales razonó que los parques nacionales habían sido establecidos por grupos de elite en Bolivia y como una especie de reserva de recursos naturales. Las autoridades estatales planean iniciar perforaciones petroleras en ocho de las veintidos áreas protegidas existentes de la nación ${ }^{55}$. De acuerdo con el decreto superior 2.366 podrían extraerse hidrocarburos en todas las partes de la nación y comercializarse para el bien común (bienestar social/reducción de la pobreza) ${ }^{56}$.

Asimismo, el vicepresidente García Linera declaró que debería realizarse una enmienda del estatuto sobre la intangibilidad del TIPNIS $^{57}$, que fue uno de los

53. Página Siete (2014).

54. García Linera (2013); Página Siete (2014).

55. Página Siete (2015a).

56. Morales Ayma (2015b).

57. El Día (2015). 
logros centrales de la marcha indígena de 2011 para el TIPNIS. De acuerdo con las estadísticas públicas y según los cálculos del CEDIB (Centro de Documentación e Información de Bolivia), las concesiones de petróleo y gas hoy se extienden en once de las veintidos áreas protegidas bolivianas. En TIPNIS, se supone que el 35\% del territorio está disponible para la extracción de petróleo y de gas según estas cifras $^{58}$. Morales presenta otras estadísticas sobre las proporciones afectadas por el extractivismo. Según el Presidente, el extractivismo afectará solo el 0,0008\% (205 ha) del territorio de siete áreas protegidas (3.900.000 de ha, cada una con un tamaño promedio de 560.000 ha). En cuanto al derecho de la población afectada a una consulta previa, libre e informada, debatida a lo largo de los conflictos del TIPNIS, Morales ha expresado reiteradamente que considera este procedimiento como una pérdida de tiempo y dinero, pero que este derecho de los pueblos debe ser respetado ${ }^{59}$.

A principios de octubre de 2015, el Ministro de Energía e Hidrocarburos anunció que contaba con el apoyo de cerca de cincuenta comunidades indígenas afectadas (en su mayoría guaraníes) en los departamentos de Tarija, Santa Cruz y Chuquisaca, relativamente a la explotación de hidrocarburos en las áreas protegidas. El ministro de Energía e Hidrocarburos, Luis Alberto Sánchez, se refirió a las cartas de los grupos indígenas interesados que expresaron su apoyo a los planes de desarrollo en sus regiones. Como afirmaron, ellos deseaban "tener la misma posibilidad que otros de tener una escuela, hospital, caminos" ${ }^{60}$.

El exministro de Planificación de Bolivia, el sociólogo René Orellana Halkyer, reflexiona sobre los desafíos y dilemas éticos, políticos y económicos del país:

"No puede ser que los derechos de unos están en contra de los derechos de otros. ¿Cuáles derechos son más importantes? Es la pregunta que políticamente se hacen muchos políticos: ¿Son más importantes los derechos de la Madre Tierra? ¿Son más importantes los derechos indígenas? ¿Son más importantes los derechos de todos los ciudadanos bolivianos? Esta es una pregunta que bien podrías aplicar a la carretera de TIPNIS, o la exploración petrolera en las áreas protegidas cuyos réditos económicos van a beneficiar a todos los bolivianos. ¿Entonces cuáles derechos son? ¿Son los derechos económicos, sociales y culturales de los ciudadanos bolivianos, los derechos

58. Hill (2015).

59. OIEDC (2015).

60. Página Siete (2015 b). 
de los pobres del país? Los cuatro deben ser complementarios... Está bien los mecanismos de consulta, pero también el beneficio y la necesidad que tiene el resto de los bolivianos, este es un debate muy importante porque ahora se le dice a Bolivia: ¿Bolivia, si quiere proteger la Madre Tierra, porqué explota el petróleo y el gas? ¿Pero si nosotros no tenemos el gas, con qué financiamos las escuelas y la salud?" ${ }^{61}$.

Resumiendo, el caso del TIPNIS puede ser visto como una ilustración de la superioridad de los derechos definidos por clase frente a los derechos étnicos, como se ha reflexionado, por ejemplo, cuando el gobierno expresa su justificación detrás del proyecto en sus discursos.

\section{Indigeneidad y la paradoja del desarrollo extractivista}

Las lógicas capitalistas de acumulación siguen siendo atributos centrales de la economía política boliviana, un desarrollo que ha sido criticado por muchos activistas y estudiosos que esperaban ser testigos del ascenso de un proyecto anticapitalista/ postcapitalista en el país ${ }^{62}$. Sin embargo, desde el principio, el gobierno de Morales ha comunicado explícitamente que el Estado debe conseguir el control de las industrias extractivas para poder financiar las reformas para el bienestar social y lograr el desarrollo económico. Igualmente, como argumentó Almut Schilling-Vacaflor, el gobierno de Morales realizó reformas legales radicales en relación con los derechos humanos y a los principios medioambientales en el ámbito del sector de los hidrocarburos. Estas mejoras, incluido el reconocimiento de algunos derechos en la Constitución de 2009, fueron los resultados de décadas de lucha popular, sobre todo de los pueblos indígenas de las tierras bajas ${ }^{63}$.

Evidentemente, los debates sobre el indigeneidad y los derechos de los pueblos indígenas, expresados, por ejemplo, por las ONG y las Naciones Unidas, podrían funcionar mejor en el ámbito de Estados nacionales en los cuales los pueblos indígenas representan una minoría. En Bolivia, desde 2006, a veces clasificada como "Estado indígena", los pueblos indígenas constituyen la mayoría y el caso boliviano

61. Orellana Halkyer, entrevista, La Paz, 31 de enero, 2014. Orellana tiene un Ph.D. en Sociología y fue el portavoz de Bolivia en las cumbres climáticas. Asimismo, fue coautor de la Ley de la Madre Tierra.

62. Hollender (2016).

63. SChilling-VACAFLor (2013), p. 207. 
muestra una serie de complejidades y contradicciones en cuanto a las reivindicaciones de los derechos indígenas y al significado de indigeneidad ${ }^{64}$. Del mismo modo, el discurso del indigeneidad ha sido utilizado estratégicamente tanto por el gobierno como por los activistas de la oposición ${ }^{65}$.

Durante las entrevistas en Amazonas (Departamento de Beni) tuve el privilegio de discutir sobre el elemento de la territorialidad como criterio fundamental del indigeneidad (mencionado en el artículo 30 de la Constitución) con un líder mosetén y una activista no indígena. Ambos expresaron una definición más fundamentalista de la territorialidad como un criterio superior de la indigeneidad y, siguiendo esa lógica, ni los bolivianos urbanos ni los migrantes de herencia indígena podrían calificarse como originarios-indígenas. Por la misma razón argumentaron que las únicas organizaciones originarias-indígenas "puras” serían CONAMAQ y CIDOB"6 .

El educador quechua Leonel Cerruto no está de acuerdo. Afirma que también los individuos y las colectividades indígenas urbanas y emigrantes cumplen con los criterios de indigeneidad, igual que la CSUTCB, las Bartolinas y las organizaciones interculturales. En primer lugar, argumenta, los pueblos indígenas siempre han sido móviles; Por lo tanto, es muy frecuente que sea complicado definir el exacto origen indígena de un grupo étnico. Por otra parte, en relación con la Constitución y a los dilemas internos del más amplio movimiento indígena, él opina:

"Indígena-originario-campesino sin comas va a entrar a la Constitución como una sola palabra, para no estar fragmentando ni peleando, dividiéndonos entre nosotros, porque el indígena, originario y campesino manejan la territorialidad. Para nosotros siempre ha sido el principio de tierra y territorio, ambas cosas, no solamente ni tierra ni territorio, sino tierra y territorio como principios de vida. Entonces, eso nos ha permitido rearticularnos, pero todavía existe esa falsa visión de que el campesino no es indígena etcétera. Lo único que hace es dividir, cuando se necesita unificar" ${ }^{67}$.

En una conversación anterior de principios de 2011, el líder de la CSUTCB, Damián Condori, articuló lo siguiente en cuanto a la identificación tanto en términos de clase como de etnicidad (en relación con las formulaciones en la nueva Constitución):

64. CANESSA (2014).

65. Fabricant (2013); Mcneish (2013).

66. Entrevistas anónimas, Rurrenabaque, 16 de noviembre de 2015.

67. Cerruto, entrevista, El Alto, 23 de noviembre de 2015. 
"Sí, nosotros normalmente ya nos estamos acostumbrando, diciéndonos entre todos, nosotros somos indígenas, originarios, campesinos, ya no solo soy campesino, somos campesinos, indígenas, originarios en Bolivia la mayor parte casi $65 \%$ entre indígenas, originarios, campesinos, porque campesino más suena en Bolivia, la Confederación Única de Campesinos en Bolivia, CSUTCB, está presente en los 9 departamentos, tenemos ejecutivos de las federaciones departamentales en los 9 departamentos, mientras los CONAMAC quienes se identifican como originarios, que es el Consejo Nacional de Ayllus y Markas solo están en lunares y además el 98 recién se ha fundado, entonces más está en Oruro, en La Paz una parte, en Potosí también" 68 .

Anders Burman ofrece una interesante observación sobre las fluctuaciones de las identidades étnicas. Los pueblos indígenas de las tierras altas se identificaron como "originarios" y se referían a los pueblos de las tierras bajas como indígenas. Burman se refiere a sus reuniones con las autoridades del CONAMAQ, que en 2001 se sintieron perplejas al ser etiquetadas como "indígenas", ya que los indígenas -según ellos- eran los pueblos de las tierras bajas, mientras que las tierras altas aimara y quechua se identificaban como originarios. En 2011, durante las protestas de TIPNIS, esta identificación semántico-cultural se alteró y los portavoces de CONAMAQ ahora se identificaban y marchaban como "indígenas", es decir, identificándose con una lucha más amplia, involucrando, también, a los pueblos indígenas de las tierras bajas ${ }^{69}$. Por ende, la indigeneidad estratégica de esa manera puede evolucionar en diferentes direcciones; ya sea a través de la "etnificación" de actores que anteriormente eran muy clasistas, o, como en este caso con el CONAMAQ, pasando de originarios a indígenas.

El discurso étnico-indígena y clasista de Evo Morales y su gobierno es pronunciado y dirigido a diferentes niveles; las esferas nacional y global respectivamente. Siendo de origen aimara, la identidad étnica del Presidente es extremadamente importante en términos de capital simbólico étnico. Si bien él es ante todo un sindicalista campesino y líder de los cocaleros, la identidad indígena, aunque se funda en el clasismo, es esencial tanto en los discursos nacionales como en los internacionales.

68. Condori, entrevista, Sucre, 10 de enero de 2011.

69. BURMAN (2014). 
Sin embargo, por lo que concierne a la posición fortalecida de la indigeneidad en la forma actualizada de la ciudadanía -especialmente en comparación con la identificación anterior de los pueblos indígenas como campesinos, resultado de la revolución agraria de 1952- es indispensable proporcionar una imagen más amplia al examinar la indigeneidad dentro del proyecto político de la administración Morales. Evo Morales ha sido pintado como un héroe del clima en todo el mundo, apoyándose en los discursos basados en los valores indígenas y en la cosmovisión del Vivir Bien (Suma Qamaña) como opciones tanto para la crisis del capitalismo global como para la crisis climática. Pero este discurso se aplica sobre todo en el ámbito global, mientras que los discursos en el nacional de Morales se ocupan más del desarrollo económico y de la distribución equitativa de los recursos, es decir, las políticas y los derechos definidos por la clase y la justicia social ${ }^{70}$. La ministra de Ambiente, Alexandra Moreira, reflexiona sobre los desafíos que Bolivia enfrenta en cuanto al desarrollo, y considerando los principios del Vivir Bien:

“...Se tiene que utilizar nomás la palabra de desarrollo. El desarrollo, el progreso del país tiende también a mejorar la calidad de vida del ser humano y, por supuesto, del ser humano boliviano. Entonces, yo creo que el mensaje tal vez en el mundo entero también ha sido comprendido de manera incompleta, el que nosotros defendamos a la madre tierra. Que defendamos el Vivir Bien no quiere decir que nosotros vamos a quedarnos en un retroceso ni tecnológico, ni de desarrollo, por supuesto, menos humano"71.

Considerando esta declaración -y la citación anterior de Huanacuni Mamani sobre la imposibilidad de hablar del Vivir Bien sin tener garantías de un mínimo nivel de dignidad social de los ciudadanos- parece indiscutible que lo más importante para el gobierno fue plantear el problema y proponer el Vivir Bien como una opción para el mundo. La ambición no fue la de abandonar completamente la tradición de desarrollo según las pautas del capitalismo y dejar de contaminar la naturaleza mediante el extractivismo. La superioridad relativa de las políticas de bienestar social vis-à-vis la conservación ambiental y de manera indirecta también los derechos territoriales indígenas, se refleja igualmente en la afirmación.

70. Análisis del autor de discursos públicos y observaciones durante trabajo de campo (20102016). Véase también: Postero (2013); Fabricant (2013).

71. Moreira, entrevista, La Paz, 14 de abril de 2015. 
El gobierno por lo general aplica un enfoque pragmático hacia los derechos étnicos y ambientales. La Constitución de 2009 incluye artículos que favorecen esa actitud hacia estos derechos, si los ingresos de las actividades extractivas se utilizan para el bien común y la redistribución económica ${ }^{72}$. En consecuencia, siguiendo este razonamiento, si los intereses de clase definen las políticas prioritarias dirigidas al bien común y la redistribución económica, los derechos étnicos y ambientales pueden ser eludidos.

Sin embargo, las relaciones y las tensiones entre la clase, la etnicidad y el ecologismo son, como se ha dicho, más complejas. El antropólogo John-Andrew McNeish enfatiza la complejidad de la identidad-política boliviana y de la indigeneidad. Como él argumenta, se encuentra un frecuente malentendido de los analistas en la simplificación y generalización de la relación entre clase y etnicidad. Tampoco debe interpretarse el conflicto TIPNIS como tal, es decir, como una batalla entre activistas indígenas y ecologistas, por un lado, y la posición desarrollista y clasista del gobierno, por el otro. Incluso, si estos intereses específicos realmente existen, las realidades acerca de la identificación étnica y basada en la clase de los pueblos indígenas son más complejas y fluctuantes. Las comunidades indígenas se han adaptado a las prácticas capitalistas, consumistas y desarrollistas desde muchas décadas, que han dado lugar a repercusiones en las identidades colectivas e individuales ${ }^{73}$.

Debe destacarse igualmente que las reivindicaciones de las poblaciones indígenas rurales hacia el Estado -tanto entre los partidarios de oposición como del gobierno- por lo general tienen más que ver con la infraestructura, la salud y la educación que con la preocupación ecológica o los derechos étnico-culturales, como se percibió durante el trabajo de campo en Amazonas (Departamento de Beni), así como en las tierras bajas del Chaco (Departamento de Santa Cruz) ${ }^{74}$.

Al redondear, el dilema extractivista ha caracterizado los últimos años de conflictos políticos y de gestión de recursos en Bolivia. A menudo, estos conflictos han sido interpretados como opciones entre valores y derechos étnicos y ambientales por un lado y -de acuerdo con McNeish-intereses y valores económicos, desarrollistas y definidos por clase, por el otro. La realpolitik es siempre una cuestión de elecciones y prioridades, y siempre habrá un cierto grado de compromisos y sacrificios de derechos, intereses y valores específicos.

72. LALANDER (2015).

73. MCNeISH (2013), p. 238.

74. Observaciones y entrevistas del autor, noviembre-diciembre de 2015. 


\section{Conclusiones}

En este artículo he examinado los derechos étnicamente definidos en relación a los derechos humanos más amplios y definidos por clases en el contexto histórico de la política de desarrollo extractivista del gobierno de Evo Morales. Por un lado, se han examinado los derechos étnicos (y la identidad) en relación con los derechos/ identidades definidos por clase, aunque teniendo en cuenta que estas bases identitarias están entrelazadas de forma compleja e íntima en la historia contemporánea boliviana. Por otra parte, el reconocimiento relativo de estos derechos fue inspeccionado desde la perspectiva de la economía política boliviana y es condicionado por el dilema del desarrollo extractivo.

La identidad étnica de las poblaciones indígenas bolivianas es multifacética y una gran parte de ellas han preferido identificarse principalmente en términos de clase, como campesinos, aunque, al mismo tiempo, reconocen su identidad étnica. La indigeneidad en Bolivia está en gran medida condicionada por el elemento de identificación de clase, particularmente en las organizaciones centrales detrás del gobierno de Morales. Bolivia es un caso ejemplar que demuestra cómo ni las identidades ni los movimientos sociales pueden ser considerados como categorías estáticas. Ellas mudan con los cambios históricos y sociales y con las relativas posiciones de los individuos y de las colectividades en una estructura específica. En términos generales, la identidad étnico-indígena se ha ido consolidando gradualmente durante el gobierno de Morales y es posible hablar de este proceso en términos de descolonización y relativa dignificación de los pueblos indígenas.

La incorporación de la filosofía indígena del Vivir Bien en la Constitución y las políticas de desarrollo nacional ha fortalecido el perfil étnico-ecologista del gobierno de Morales, particularmente en el ámbito global. Del mismo modo, como se ha argumentado, el gobierno utiliza estratégicamente estos discursos étnicoecologistas. A través del artículo se ha mostrado que, en la práctica boliviana, los derechos étnicos (entrelazados con los ambientales) con frecuencia tienden a ser degradados en relación con los derechos más amplios definidos por clase, como resultado del dilema extractivo. Mientras que los derechos indígenas fueron reforzados de manera decisiva con la reforma constitucional de 2009, estos derechos chocan con los constitucionalmente reconocidos del Estado Nacional de extraer y comercializar recursos naturales (en especial hidrocarburos y minería) bajo la bandera de la justicia redistributiva, reformas sociales y el bien común, es decir, desde los derechos definidos por clase. Esta es una expresión crucial del dilema del desarrollo extractivo. 
La relativa superioridad de los derechos definidos por clase frente a los derechos étnico-territoriales es igualmente evidente al examinar la justificación del gobierno de los proyectos extractivos y la construcción contenciosa de la carretera a través del territorio del TIPNIS. Resumiendo, sobre la base del material examinado en este estudio, es posible concluir que los derechos étnicos (y ambientales) están frecuentemente subordinados a los derechos sociales más amplios definidos por clase, como consecuencia del dilema del desarrollo extractivo.

\section{Agradecimientos}

El autor quiere reconocer la importancia del financiamiento aportado por el Consejo Sueco de Investigación sobre Medio Ambiente, Ciencias Agrícolas y Planificación Espacial/FORMAS (www.formas.se ), entre 2013 y 2016. Igualmente un agradecimiento a todas las personas que apoyaron al proyecto y mis actividades en Bolivia, como Fernando Galindo, Elizabeth Huanca, Leonel Cerruto, Oscar Vega, Pedro Portugal, Xavier Albó y todos los actores que tuve el privilegio de entrevistar. Del mismo modo, se quiere agradecer a los colegas del Instituto de Estudios Latinoamericanos, Universidad de Estocolmo, en especial a Chiara Lenza, Magnus Lembke y Andrés Rivarola.

\section{Referencias}

Albó, Xavier (2009): Movimientos y poder indígena en Bolivia, Ecuador y Perú (La Paz, CIPCA), 294 pp.

Artaraz, Kepa (2012): Bolivia. Refounding the Nation (London, Pluto Press), 256 pp.

Artaraz, Kepa y Calestani, Melania (2015): "Suma Qamaña in Bolivia. Indigenous Understandings of Well-being and Their Contribution to a Post-Neoliberal Paradigm”. En Latin American Perspectives, Vol. 42, No 5, pp. 216-233.

Arteaga, Claudia y MuÑoz, Gerardo (2014): "La disponibilidad de lo inédito: entrevista a Silva Rivera Cusicanqui”. Disponible en: http://anarquiacoronada.blogspot.com.ar/2014/04/la-disponibilidad-de-lo-inedito.html [Fecha de consulta: febrero de 2017].

BECKER, Marc (1995): “Indigenismo and Indian Movements in Twentieth-Century Ecuador”, ponencia del Congreso de LASA (Latin American Studies Association), Washington. Disponible en: http://lanic.utexas.edu/project/ lasa95/becker.html [Fecha de consulta: febrero de 2017]. 
Belliera, Irène y PréAud, Martin (2012): "Emerging issues in indigenous rights: transformative effects of the recognition of indigenous peoples". En The International Journal of Human Rights, Vol. 16, No 3, pp. 474-488.

Burman, Anders (2014): “Now we are Indígenas': Hegemony and Indigeneity in the Bolivian Andes". En Latin American and Caribbean Ethnic Studies, Vol. 9, $\mathrm{N}^{\circ}$ 3, pp. 247-271.

CANESSA, Andrew (2014): "Conflict, claim and contradiction in the new 'indigenous' state of Bolivia”. En Critique of Anthropology, Vol. 34, N 2, pp. 153-173.

CSUTCB/ Confederación Sindical Única de Trabajadores Campesinos de Bolivia (2010): Estatuto Orgánico de la CSUTCB, Santa Cruz, 30 de Julio de 2010. Disponible en: http://comisionorganica-csutcb.blogspot.se/2012/09/estatutoorganico-de-la-csutcb-aprovado.html [Fecha de consulta: febrero de 2017].

El Día (2015): Gobierno busca anular la "intangibilidad" del Tipnis, 28 de junio de 2015. Disponible en: http://eldia.com.bo/index.php?cat=1\&pla=3\&id_articulo=174956 [Fecha de consulta: febrero de 2017].

Escobar, Arturo (2010): "Latin America at a Crossroads. Alternative Modernizations, or Post-Development?”. En Cultural Studies, Vol. 24, No 1, pp. 1-65.

Estado Plurinacional de Bolivia (2009): Constitución Política del Estado (La Paz: Estado Plurinacional de Bolivia).

Estado PluRinacional de Bolivia (2012): Ley Marco de la Madre Tierra y Desarrollo Integral para Vivir Bien (La Paz: Asamblea Legislativa del Estado Plurinacional de Bolivia).

Fabricant, Nicole (2013): “Good Living for Whom? Bolivia's Climate Justice Movement and the Limitations of Indigenous Cosmovisions". En Latin American and Caribbean Ethnic Studies, Vol 8, No 2, pp. 159-178.

Fontana, Lorenza Belinda (2014): "Indigenous Peoples vs Peasant Unions: Land Conflicts and Rural Movements in Plurinational Bolivia". En The Journal of Peasant Studies, Vol. 41, No 3, pp. 297-319.

FundaCión TIERRA (2012): Marcha indígena por el TIPNIS. La lucha en defensa de los territorios (La Paz, Comunicaciones El País S.A. Fundación Tierra), 302 pp.

García Linera, Álvaro (2012): Geopolitica de la Amazonía. Poder hacendalpatrimonial y acumulación capitalista (La Paz, Vicepresidencia del Estado Plurinacional de Bolivia), 113 pp.

García Linera, Álvaro (2013): Los desafíos del proceso de cambio en Bolivia, Conferencia en el Centro Cultural de Cooperación Floreal Gorini, Buenos Aires, 27 de junio, 2013. Disponible en: www.centrocultural.coop/videos/ la-patria-grande-alvaro-garcia-linera--1-.html [Fecha de consulta: febrero de 2017]. 
García Yapur, Fernando, García Orellana, Luis Alberto y Soliz Romero, Marizol (2014): "MAS legalmente, IPSP legitimamente". Ciudadanía y devenir Estado de los campesinos indígenas en Bolivia (La Paz, PIEB, PNUD), 402 pp.

Gray Molina, George (2007): "Ethnic Politics in Bolivia:'Harmony of Inequalities'1900-2000”, Working paper, (University of Oxford Centre for Research on Inequality, Human Security and Ethnicity/CRISE), 35 pp.

Gudynas, Eduardo (2011): “Buen Vivir: Today’s Tomorrow”. En Development, Vol. 54, N 4, pp. 441-447.

GudynAs, Eduardo (2015): Extractivismos. Ecología, economía y politica de un modo de entender el desarrollo y la Naturaleza (Cochabamba, CLAES y CEDIB), 453 pp.

Hill, David (2015): Bolivia opens up national parks to oil and gas firms. En The Guardian, 5 de junio de 2015. Disponible en: www.theguardian.com/environment/andes-to-the-amazon/2015/jun/05/bolivia-national-parks-oil-gas [Fecha de consulta: febrero de 2017].

Hollender, Rebecca (2016): “Capitalizing on Public Discourse in Bolivia - Evo Morales and Twenty-first Century Capitalism”. En Consilience: The Journal of Sustainable Development, Vol. 15, N 1 , pp. 50-76.

KRECH III, Shepard (1999): The Ecological Indian: Myth and History (New York: W. W. Norton \& Co.), 318 pp.

LALANDER, Rickard (2014): "Rights of Nature and the Indigenous Peoples in Bolivia and Ecuador: A Straitjacket for Progressive Development Politics?”. En Iberoamerican Journal of Development Studies, Vol. 3, No 2, pp. 148-172.

LALANDER, Rickard (2015): “Entre el ecocentrismo y el pragmatismo ambiental: Consideraciones inductivas sobre desarrollo, extractivismo y los derechos de la naturaleza en Bolivia y Ecuador". En Revista Chilena de Derecho y Ciencia Política, Vol. 6, No 1, pp. 109-152.

LALANDER, Rickard y KRÖGER, Markus (2016): “Extractivismo y derechos étnicoterritoriales de jure y de facto en Latinoamérica: ¿Cuán importantes son las constituciones?”. En Observatorio del Desarrollo, CLAES/Centro Latinoamericano de Ecología Social, No 23, pp. 1-21.

McNeISH, John-Andrew (2013): "Extraction, Protest and Indigeneity in Bolivia: The TIPNIS Effect". En Latin American and Caribbean Ethnic Studies, Vol 8, $\mathrm{N}^{\mathrm{o}}$ 2, pp. 221-242.

Mignolo, Walter (2002): "DELINKING. The rhetoric of modernity, the logic of coloniality and the grammar of de-coloniality". En Cultural Studies, Vol. 21, $\mathrm{N}^{\mathrm{o}} 2$, pp. 449-514. 
Monasterios, Karin, Stefanoni, Pablo y Do Alto, Hervé (2007): Reinventando la nación en Bolivia: movimientos sociales, Estado y poscolonialidad (La Paz, Plural editores), $171 \mathrm{pp}$.

Morales Ayma, Evo (2015a): Discurso presidencial 639 (La Paz, Ministerio de Comunicación, Estado Plurinacional de Bolivia), 7 de agosto de 2015. Disponible en: www.comunicacion.gob.bo/sites/default/files/media/discursos/Discurso $\% 20$ Presidencial\%2007-08-15.pdf [Fecha de consulta: febrero de 2017].

Morales Ayma, Evo (2015b), Decreto Supremo No 2366 (La Paz, Estado Plurinacional de Bolivia).

OIEDC/ Observatorio de Industrias Extractivas y Derechos Colectivos (2015): "Evo: En la consulta previa se pierde mucho tiempo", 13 de Julio de 2015. Disponible en: http://oiedc.blogspot.se/2015/07/evo-en-la-consulta-previase-pierde.html [Fecha de consulta: febrero de 2017].

PÁgINA SIETE (2014): El Vicepresidente descarta carretera por el TIPNIS. 4 de enero, 2014. Disponible en: www.paginasiete.bo/nacional/2014/1/4/vicepresidentedescarta-carretera-tipnis-10441.html [Fecha de consulta: febrero de 2017].

PÁgINA SIETE (2015a): Bolivia se sumó a la corriente de explotar áreas protegidas, 24 de junio de 2015. Disponible en: www.paginasiete.bo/nacional/2015/6/24/ bolivia-sumo-corriente-explotar-areas-protegidas-60974.html [Fecha de consulta: febrero de 2017].

PÁgina Siete (2015b): Indígenas de 50 pueblos dieron aval para tareas de exploración, 3 de octubre de 2015. Disponible en: www.la-razon.com/economia/ Gobierno-indigenas-pueblos-dieron-aval-tareas-exploracion_0_2355964414. html [Fecha de consulta: febrero de 2017].

Portugal Mollinedo, Pedro (2017): "El Indianismo como Proyecto Político". Disponible en: http://carlosmacusaya.blogspot.se/2017/02/el-indianismocomo-proyecto-politico.html [Fecha de consulta: febrero de 2017].

Portugal Mollinedo, Pedro y Macusaya Cruz, Carlos (2016): El Indianismo Katarista. Un análisis crítico (La Paz: Fundación Friedrich Ebert/FES), 599 pp.

Postero, Nancy G. (2007): Now We Are Citizens. Indigenous Politics in Postmulticultural Bolivia (Stanford University Press), 294 pp.

Postero, Nancy (2013): "Protecting Mother Earth in Bolivia: Discourse and Deeds in the Morales Administration". En CoOPER, James M. y HunefeldT, Christine (editores), Amazonía. Environment and the Law in Amazonia: A Plurilateral Encounter (Brighton: Sussex Academic Press), pp. 78-93.

Schilling-VACAFlor, Almut (2013): "Prior Consultations in Plurinational Bolivia: Democracy, Rights and Real Life Experiences”. En Latin American and Caribbean Ethnic Studies, Vol. 8, No 2, pp. 202-220. 
UlloA, Astrid (2005): The Ecological Native. Indigenous Peoples Movements and Eco-Governmentality in Colombia (New York, Routledge), 314 pp.

ValtmeYer, Henry (2014): "Bolivia: Between Voluntarist Developmentalism and Pragmatic Extractivism”. En ValtMeYer, Henry y Petras, James (editors), The New Extractivism. A Post-Neoliberal Development Model or Imperialism of the Twenty-First Century? (Londres y Nueva York, Zed Books, 2014): pp. 80-113.

WALSH, Catherine (2009): "The Plurinational and Intercultural State: Decolonization and State Re-Founding in Ecuador", En Kult, Department of Culture and Identity, Roskilde University, $\mathrm{N}^{\circ}$ 6: pp. 65-84. 